Chirurgia (2017) 112: 627-629

No. 5, September - October

Copyright@ Celsius

http://dx.doi.org/10.21614/chirurgia.112.5.627

\title{
Is There a Threat Towards Medical Institutions, and What to Do?
}

\section{Mike Bemelman}

St Elisabeth Two-cities Hospital , Dept of Surgery, Tilburg, The Netherlands

Corresponding author:

Mike Bemelman, MD

St Elisabeth Two-cities Hospital

Department of Surgery, Tilburg

The Netherlands

E-mail: M.Bemelman@etz.nl
Received: 23.08.2017 Accepted: 02.09.2017
Unfortunately the reality of today is that a terrorist threat in Europe has become evident. With increasing frequency we are confronted with attacks all across Europe, at least this is the perception. So is there a Threat? If look at the paper of Wolf et al (1), this describes an increase of terrorist attacks from 19992006 , the amount of victims due to these attacks increased exponentially. This means the attacks are getting more effective. The perpetrators are getting better and are learning how to injure or kill more victims. The techniques are getting more sophisticated. For example if we look at the Bali Bombing in 2002, here a second hit technique is used. The terrorist placed first a small bomb in a tourist area, knowing that this eventually will attract many people who rush in to help the victims. Then a second hit was done with a much larger bomb killing and wounding even a larger group of people. This is the goal of the terrorist, introducing terror, shocking the world, introduce fear. If we look at the attack in Nice, South France. They used a truck driving through a large tourist crowd, knowing that there would be many children and young people. This is their ultimate goal, shock the world.

With that mindset, just imagine how shocking would it be to primary attack a medical institution. Our weakness as medical people is that we want to help people, In fact we gave a Hippocratic oath that we will always help other people, that is our job. We find it hard to believe that medical relief institutions will be attacked. If we look at the London bombing in 2005, one of the terrorists detonated the bomb in a bus. By coincidence this happened right in front of the British Medical Association with 
many doctors in the building at that time. All of them immediately went to the exploded bus to provide medical relieve, did they even think for a second that there maybe would be a second hit? We are to nice, and the terrorists know this.

Historyhas proven to us that medical institutions are a potential goal. 2008 a terror attack in Mumbai, eight series of attacks were done between $26-29^{\text {th }}$ of November. Eventually the terrorist where heading for the CAMA hospital. However because the hospital was alerted and were able to perform a complete lock down they were able to prevent additional casualties in the hospital itself. Are these rare incidents?

Unfortunately not, Ganor et al (2) describe 100 terror attacks on medical institutions in 43 countries worldwide, killing 775 people.

The most recent incident a terror attack on the Sardar Mohammad Daud Khan hospital in 2017, killing approx. 40 and wounding 50 people.

The health and human services in the US has issued a statement in January 2017 that hospitals have to be aware for terrorist attacks. A report written by C. Hancock in 2006 (3) entitled "thinking the unthinkable". They Highlight that hospitals are not prepared to cope with attacks when they become targets themselves. "It is the Unthinkable ......" . As stated above, we are to nice. We think that we will not become a target, we think people don't attack medical institutions....

The Threats analysis performed by $R$. Faccincani proves this. A European funded Risk analysis of terrorist threats in the health sector in 28 countries, 40 responders. $80 \%$ stated that it is unlikely that a hospital will be a target. In the unlikely event that a hospital will be targeted approx. $60 \%$ acknowledge that they are unprepared. This analysis confirms that in general we as medical institutions don't believe that we will become a target, however we realize that we are unprepared in the unlikely event and luckily we all are willing to do something about it. Looking at history we have to conclude that the heath sector is a target and it is our responsibility to prepare and deal with this issue. To my opinion this starts with creating awareness.
We have to raise awareness within the health sector and not only within the management, but with all personnel working in the health sector. Because we have to be realistic that one can never prevent attacks $100 \%$. However when institutions are aware and prepare for such events, one can reduce the chances of becoming a target. Personnel should be aware that something can happen and thus keep their eye open and report suspicious circumstances. Management together with the security department have to realize that 2 general scenarios are possible. $1^{\text {st }}$ The hospital being a primary target and $2^{\text {nd }}$ the hospital being a secondary target after an initial strike outside the hospital.

Security personnel should criticallyanalyze the lay out of the hospital and take subtle measure to prevent direct attacks. Eg introducing large concrete flower beds in front of the entrance preventing the possibility of a vehicle driving into the crowd. Of course a fine balance has to be made between preventive measures and the logistic business of a hospital. The daily routine should not be impaired by these measures. The security department should also incorporate a protocol, in the unlikely event of an attack, dictating collaboration with law enforcement / military institutions. A hospital should be prepared to perform a complete lockdown, especially if there is a threat in the sense of a second hit after an incident outside the hospital. Prehospital personnel should be familiar with such a lockdown possibility. Security must be trained and have the material and capacity to close down all traffic towards the hospital and perform a quick search of vehicles requiring entrance to the hospital.

In order to reach this kind of level of preparedness, specific education and training is mandatory. This kind of preparation is of course no regular business for hospitals, they lack the experience and knowhow, so external expertise is essential. Collaboration with law enforcement, inland security and military should be pursued. Seek advice and knowledge with institutions who have dealt with incidents like this before. After implementing measures to 
increase the level of security, regular training, of course, will be essential. Training programs within the institution and outside the hospital together with the national departments (eg. police) will be the backbone for effective protocols.

Because: "knowing is not enough; we must apply" "Willing is not enough, we must do" (Goethe).

\section{References}

1. Wolf SJ, Bebarta VS, Bonnett CJ, Pons PT, Cantrill SV. Blast injuries. Lancet. 2009;374(9687):405-15. doi: 10.1016/ S0140-6736(09) 60257-9. Epub 2009 Jul 22.

2. Ganor B, Halperin Wernli M. Working paper 25, october 2013. Terrorist Attacks against Hospitals - Case Studies. ICTWPS. 2013. p. 1-32.

3. http://www.dcs.gla.ac.uk/ johnson/papers/NHS_terrorism.pdf 